\title{
"EL LUGAREÑO" CONTRA LA ESCLAVOCRACIA: LAS CARTAS DE GASPAR BETANCOURT Y CISNEROS (1803-1866)
}

POR

\author{
MANUEL DE PAZ SÁNCHEZ \\ Universidad de La Laguna
}

Gaspar Betancourt y Cisneros, "El Lugareño", miembro destacado del sector intelectual y propietario de las clases dominantes cubanas durante la primera mitad del siglo $X I X$, constituye sin duda un ejemplo del máximo interés para entender algunos de los aspectos esenciales del profundo debate, producido durante aquella época, entre el sector minoritario de elementos opuestos a la esclavitud, por entender que los viejos tópicos de la idoneidad de la fuerza de trabajo esclava eran un freno al desarrollo de la propia producción azucarera, y la mayoría de grandes propietarios que confiaban aún en una explotación ilimitada de los recursos humanos ligados a la trata y a su explotación agraria. Las cartas de nuestro personaje a algunos de sus seguidores y amigos, especialmente a Domingo del Monte, constituyen en este sentido, un testimonio de primera mano sobre la intensidad del problema.

\section{INTRODUCCIÓN}

La familia Betancourt llegó a Santiago de Cuba, procedente de La Laguna (Tenerife), a mediados del siglo XVII, tal como nos relata Francisco $\mathrm{X}$. de Santa Cruz y Mallen, conde de Jaruco y Mopox, en su Historia de familias cubanas ${ }^{1}$.

Esta dinastía familiar dio lugar a varias ramas, entre las que destaca la propia de la capital oriental y la llamada, por el genealogista antes citado, "línea de Puerto Príncipe", por referencia al antiguo nombre del Camagüey. Nuestro protagonista, como otros de su linaje, nació del matrimonio endogámico de don Diego Antonio de Betancourt y Aróstegui con doña

1 Francisco X. DE SANTA CRUZ y MALlen, Historia de familias cubanas, La Habana, Ed. Hércules, 1943, t. IV, p. 70. 
María de Loreto Cisneros y Betancourt, celebrado el 8 de enero de 1800 en la catedral de Puerto Príncipe ${ }^{2}$.

Gaspar Alonso Betancourt y Cisneros fue bautizado, en la mencionada catedral del Camagüey, el día 29 de abril de 1803, y, tal como afirma sintéticamente Santa Cruz y Mallen, "fue síndico del Ayuntamiento en 1840, distinguido escritor y periodista con el seudónimo de El Lugareño. Iniciador del ferrocarril de Camagüey a Nuevitas. Su defunción se encuentra en La Habana, parroquia de Guadalupe, a 12 de diciembre de 1866, siendo enterrado en Camagüey. Casó en la Habana el 7 de septiembre de 1857, con doña María Monserrate Canalejo e Hidalgo-Gato", y tuvo un hijo, Alfonso Betancourt y Canalejo, nacido en Florencia (Italia), en febrero de $1859^{3}$.

Tal como relató el propio Betancourt años más tarde a otro de sus amigos reformadores, el conde de Pozos Dulces":

Con toda idea me llamaron Gaspar Alonso, porque yo vine al mundo con los dos apellidos que trajo desde Canarias a la Isla de Cuba el fundador de nuestra familia, y deseando que en todo me pareciese a él hubieron de darme su propio nombre.

Hasta 1822 realizó estudios en Camagüey, pero en ese año fue enviado a Estados Unidos para completar su educación. Se estableció en Filadelfia y allí trabajó en una casa de comercio. No tardó en relacionarse con importantes figuras hispanoamericanas y cubanas, especialmente con José Antonio Saco. En 1823, como parte de una comisión cubana, marchó desde Nueva York a La Guaira, para entrevistarse con Bolívar a fin de promover también la emancipación de Cuba. En Estados Unidos amplió su educación y asistió a diversas reuniones de carácter político. En 1834 regresó a Cuba, donde realizó una gran labor de mejoramiento económico y social en la zona del Camagüey, como la creación de escuelas o la promoción de la línea del ferrocarril a Nuevitas, y, al mismo tiempo, colaboró en la prensa, particularmente en la Gaceta de Puerto Príncipe ${ }^{5}$, a partir de 1837, donde vieron la luz sus "Escenas cotidianas", así como numerosas cartas y artículos de opinión. Más tarde colaboró en El Fanal, de Camagüey, y en El Siglo de La Habana. En 1846 fue obligado a abandonar el país por orden del Capitán General O'Donnell, estableciéndose nuevamente en los Estados Unidos, donde desplegó una amplia labor política como presidente de la Junta Cubana en Nueva York. En esta ciudad fundó, en 1848, el periódico La Verdad, de orientación anexionista, "posición que abandonó años

Ibidem, p. 92-93.

3 Ibidem, p. 93.

4 Federico DE CóRDOVA (comp.), Cartas del Lugareño (Gaspar Betancourt y Cisneros), La Habana, Publicaciones del Ministerio de Educación, Dirección de Cultura, 1951, p. 13.

5 Eduardo LABRADA RODRíGUEZ, La prensa camagüeyana del siglo XIX, Santiago de Cuba, Ed. Oriente, 1987, pp. 25 y ss.

R. I., $1998, \mathrm{n}^{\circ} 214$ 
después para defender las ideas de independencia"6. En 1856 partió hacia Europa y se estableció en Florencia, aunque poco después se trasladó a París, regresando a Cuba en 1861. Políglota, inquieto, ilustrado y agudo reformador, falleció cinco años más tarde víctima de una dolorosa enfermedad.

A raíz de su muerte en 1866, Francisco Calcagno le dedicó una encendida crónica necrológica, con intención de publicarla en El Siglo, lo que no se le permitió, pero se vengó de esta prohibición en su valioso Diccionario Biográfico Cubano ${ }^{7}$ :

Acaba de fallecer en La Habana un hombre cuya vida toda consagrada al servicio del suelo que le vio nacer, dejará un recuerdo imperecedero en nuestros corazones cubanos; un hombre que fue para el Camagüey lo que Arango y $\mathrm{Pa}$ rreño para La Habana, un hombre en fin cuya historia pasará incólume a la posteridad, para recibir en ella tantas bendiciones como lágrimas le tributa hoy la patria agradecida.

Su rico epistolario, recogido en edición completa por Federico de Córdova $^{8}$, nos permite atisbar la honda personalidad y la franca espontaneidad de un reformador que, tras apostar por el progreso económico y social de su región de origen, se debatió en las abruptas contradicciones de un intelectual cubano de su tiempo. Betancourt Cisneros conservó, en efecto, durante toda su vida, su ilusión por el futuro de la Gran Antilla y de América, del continente joven frente a la vetustez y la decrepitud de la vieja Europa, como le recordaba a su amigo José Antonio $\mathrm{Saco}^{9}$, en carta remitida desde Roma el 11 de agosto de $1857^{10}$ :

Aquí todo me entristece. ¿Será por el estado de mi espíritu o por mis ideas? Lo cierto es que Roma me parece un Cementerio muy grande, muy solemne, de grandes hombres y glorias que se hundieron para ser reemplazadas por frailes, monigotes, lazzaroni, caricaturas y arlequines que causan lástima o desprecio. Varias tardes me he paseado en quitrín por estos contornos, y digo sin vacilar que hasta los del Camagüey me parecen jardines comparados con estos yermos y desiertos. Alguna casita o miserable pajar de millas en millas; algunos bueyes y búfalos más flacos que los de los arrieros de Guanajay, uno que otro sembradito es cuanto mis ojos han visto desde Civita-vecchia hasta la Ciudad Eterna. Lo dicho: no se me quita la idea de un gran Cementerio con todas sus basílicas, sus columnas y obeliscos, palacios y edificios antiguos y modernos. Todo me representa la vejez, canas, arrugas, carcoma y podredumbre, chochera y mugre,

6 Instituto de Literatura y Lingüística de la Academia de Ciencias de Cuba, Diccionario de la literatura cubana, La Habana, Ed. Letras Cubanas, 1980, t. I, p. 117.

7 Federico CALCAGNO, Diccionario Biográfico Cubano, New York, Imprenta y Librería de N. Ponce de León, 1878, pp. 109-112.

8 La nutrida correspondencia entre nuestro protagonista y Domingo del Monte fue publicada, a partir de 1923, por Domingo FigAROLA-CANEDA, Joaquín LLAVERÍAS Y MARTíNEZ y Manuel I. MESA RODRíGUEZ, en representación de la Academia de la Historia de Cuba, en la obra, Centón epistolario de Domingo del Monte, La Habana, Imp. Siglo XX, 1923-1957, 7 vols.

9 E. TORRES Cuevas, La polémica de la esclavitud. José Antonio Saco, La Habana, Ed. Ciencias Sociales, 1984.

10 F. DE CóRdova, [4], pp. 349-350. 
roturas, remiendos magníficos, solemnes, imponentes; pero que a mí no me sonríen ni me hacen maldita la gracia. Estoy por nuestra joven América donde todo me sonríe, me habla, me enamora con su vida y movimiento. El Vesubio pasma con su horror sublime: el Niágara embelesa y alegra el corazón. Roma es la vieja Luisa sentada en el butacón del tiempo de Cincinato: la Habana o Nueva York es Niní dando carreras y saltos, y alborotando todo el vecindario: estoy por la joven América, sin Basílicas, ni Coliseos, ni estatuas, ni ejércitos de frailes, monigotes, soldados, lazzaroni, ni mendigos que me entristecen y me revuelven alma y cuerpo, y me hacen salir de aquí sin envidiarles nada para Cuba. Quien nos la diera, hombre, así, salvajita, con sus montes vírgenes, sus bahías desiertas, sus guajiros y hasta sus criollitos prietos!... Pero si no nos la dan, hagamos por cogérnosla.

Su idea del progreso, que une la mejor tradición ilustrada con el utilitarismo asimilado durante su temprana estancia en los Estados Unidos y en sus vastas lecturas, queda reflejada en una polémica que mantuvo con el santiaguero Juan Agarrás, en las páginas de la Gaceta de Puerto Príncipe ${ }^{11}$ :

El verdadero progresista debe ser consecuente con sus principios: retrogradar, nunca; estacionarse, jamás; adelantar, siempre. ¿Alcanzó un escalón?, pues a subir otro. ¿Se apoderó de una verdad?, pues a buscar otra; y entre tanto que se desarrolle aquélla con todas sus consecuencias. ¿Hizo un camino de hierro, fundó una escuela?, pues otro y otra por otro lado: y así en el mundo intelectual como en el material, la misión del progresista es adelantar y mejorar. Le perseguirá la envidia, le asaltará la calumnia: no importa, la humanidad le defenderá porque sus tendencias y su interés es estar mejor. Se le regarán obstáculos en su camino: se dirá que su idea o su empresa es imposible, o es extemporánea, o es inútil: adelante, su respuesta sea su divisa: e pur si muove.

De aquí su obsesión por cubrir de vías férreas, como estímulo para su desarrollo económico, la región centro-oriental de Cuba. Santa María de Puerto Príncipe era, hacia 1840, la tercera ciudad más poblada de la Isla. La existencia del puerto de San Fernando de Nuevitas en la costa norte y, asimismo, el de Santa Cruz del Sur en la meridional, hicieron posible que el intercambio comercial de la región se efectuara por los mencionados puertos. Además de la ganadería, los cultivos tradicionales del país, caña de azúcar y café, constituían los renglones fundamentales de la economía camagüeyana, pero sus pequeños ingenios no podían competir con las grandes fábricas de la región occidental del país ${ }^{12}$.

En 1836, la diputación de la Sociedad Económica de Puerto Príncipe se planteó la necesidad de construir un ferrocarril que sacara de su aislamiento al comercio camagüeyano. Gaspar Betancourt Cisneros se convirtió en el paladín de la empresa. "Acompañado por los hacendados de la región, Luis Loret de Mola y Tomás Pío Betancourt, el Lugareño solicitó y obtuvo el 10 de enero de 1837, la concesión extendida por el general Miguel Tacón,

11 Ibidem, p. 233. Publicada el 5 de junio de 1839.

12 O. ZaNetTi LeCUONA y A. García ÁlvareZ, Caminos para el azúcar, La Habana, Ed. Ciencias Sociales, 1987, p. 57.

R.I., $1998, \mathrm{n}^{\circ} 214$ 
gobernador de la colonia, en favor de la construcción de un ferrocarril desde la ciudad de Puerto Príncipe hasta el puerto de Nuevitas"13.

Pero, la promoción del camino de hierro fue, sin duda, como lo expresa el propio Betancourt en carta, del 18 de septiembre de 1836, a su amigo Domingo del Monte, otro gran intelectual contemporáneo ${ }^{14}$, el primer paso de un proyecto más amplio ${ }^{15}$ :

Yo no entiendo de economía política, ni sé si esto es exacto; pero me atrevo a sostener que lo contrario es calcular intereses particulares y momentáneos, desatendiendo los generales y futuros del país. Si la Habana nos ayuda la victoria será completa, y el botín no es menos interesante en el orden físico que en el moral. Enriquecer e ilustrar a nuestro pueblo es el medio seguro de salvarle de la ruina, tal vez no muy remota. Por otra parte: si salgo bien de esta empresa, cuente $\mathrm{V}$. con que realizaré otra aún más importante y que está más en mi mano, porque casi no necesito de nadie: Yo puedo distribuir unas 18 a 20 leguas planas, con gran ventaja mía, en colonos blancos, y dado este ejemplo y demostrado el provecho pecuniario que es a lo que atienden los propietarios, tendré imitadores.

La obra ferroviaria fue encomendada al ingeniero norteamericano Benjamín $\mathrm{H}$. Wright, y la instalación de los primeros carriles se inició a comienzos de 1841. La empresa, sin embargo, experimentó diversos sinsabores, hasta que pudo ser culminada parcialmente en 1846, año en que $E l$ Lugareño abandonó la Isla. Un lustro más tarde, el ferrocarril pudo ser llevado hasta Puerto Príncipe, "completándose así los 73 kilómetros de extensión que contemplaba el proyecto de 1837”16.

\section{ELOGIO DEL PROGRESO}

En torno a 1835 , como hemos escrito en otro lugari ${ }^{17}$, la firma del segundo tratado para la supresión del tráfico africano revivió el debate, entre las clases dominantes criollas, sobre la colonización blanca. A medida que se desarrollaba el sector azucarero, la demanda de la sacarocracia se inclinó por los jornaleros y braceros libres, en contra, por lo tanto, del colono independiente y, en definitiva, de la inmigración de carácter familiar. Pese a algunas excepciones, como la promovida por el conde de Villamar en terrenos baldíos de Ciego de Avila, los proyectos de colonización habían fracasado tanto por la precariedad de recursos, cuanto por el crecimiento vigoroso de la plantación azucarera y, con ella, de la esclavitud.

13 Idem.

14 S. BuEno, Domingo del Monte, La Habana, Unión de Escritores y Artistas de Cuba, 1986.

15 F. DE CóRdOVA, [4], pp. 26-27.

16 O. Zanetti LecuONA y A. García Alvarez, [12], p. 58.

17 Manuel DE PAZ SÁNCHEZ y Manuel HERNÁNDEZ GONZÁleZ, La esclavitud blanca. Contribución a la historia del inmigrante canario en América. Siglo XIX, Santa Cruz de Tenerife, "Taller de Historia", CCPC, 1993, pp. 57 y ss. 
No obstante, el poder colonial obstaculizó las pretensiones de las clases dominantes criollas, dado que los informes reservados de los capitanes generales, tal como ha destacado Leví Marrero ${ }^{18}$, coincidían en rechazar la colonización blanca, puesto que veían un freno para las tendencias emancipadoras en el predominio cuantitativo de la población esclava.

Tanto el capitán general Jerónimo Valdés como sus inmediatos sucesores, entendieron, en efecto, que la obstaculización a la llegada de inmigrantes blancos constituía una eficaz política de sujeción colonial. Todos compartían la tesis del equilibrio racial. Valdés fue particularmente expresivo al respecto, al afirmar que los criollos eran partidarios de la independencia, y que si no lo hacían era por miedo a la raza negra y de color, "y es bien seguro que sin ese gran obstáculo la isla de Cuba no pertenecería ya a la Metrópoli, a pesar del respetable ejército que aquí se tiene. Siendo esto cierto, indudable como lo es y lo conocen los más avisados de estos naturales, claman incesantemente por el fomento de la población blanca, porque saben que el día que llegasen a tener superabundancia de ella, podrían sin peligro decir un eterno adiós a España". En consecuencia, lo prudente sería "guardar el equilibrio en la población negra y de color respecto a la blanca, procurando el aumento y conservación de la negra... por todos los medios que estén al alcance del gobierno"19.

Leopoldo O`Donnell, tras la conspiración de la Escalera en 1844, reformuló la teoría del equilibrio racial, y, si bien reconoció la necesidad de importar colonos blancos, insistió en que su penetración debería ser lenta y paulatina. De hecho, prefería braceros y proletarios capaces de insertarse sin problemas en la economía azucarera, pero reducidos a la mínima expresión. Esta política continuó con su sucesor, el conde de Alcoy, enemigo declarado de la colonización blanca, al asegurar que la raza negra era la única que podía sostener la agricultura, debiendo procurarse también la atracción de la india o mestiza americana. Chinos y yucatecos fueron, en consecuencia, soluciones parciales al problema de los trabajadores blancos en la agricultura.

Ahora bien, frente a esta política colonial existían, entre "los más avisados de estos naturales", como diría Valdés, algunos que opinaban lo contrario. En 1837, José Antonio Saco publicó en Madrid un famoso opúsculo en el que atacaba la falacia de la inadecuación de los blancos a las labores de la plantación, debido a la dureza del trabajo y por la carestía de sus salarios en relación con la fuerza de trabajo esclava. Asimismo, en 1838, Pedro José Morillas vio censurado su opúsculo Medios de fomentar y generalizar la industria, por opinar que la causa principal del atraso de la economía de plantación era que la ejercían brazos esclavos, comparando el caso de Cuba con el de Puerto Rico, donde se hacía "azúcar con brazos blancos"20.

18 L. MARRERO, Cuba: economía y sociedad. Azúcar, Ilustración y Conciencia (17631868), tomos IX y XIII, Barcelona, 1983 y 1989, especialmente, pássim.

19 Ibidem, t. IX, p. 159.

20 Ibidem, t. XIII, p. 123.

R. I., 1998, n. $^{\circ} 214$ 
Pero, fue sin duda nuestro protagonista, Gaspar Betancourt y Cisneros, el más claro exponente del punto de vista de los sectores más renovadores de las clases dominantes criollas, que apostaban por la atracción de asalariados blancos, como medio para promover la mayor rentabilidad de las explotaciones agrícolas y, asimismo, para avanzar en el camino de la emancipación nacional. Por ello promovió, a pesar de las cortapisas estatales, la inmigración de colonos catalanes y canarios como uno de sus objetivos político-económicos de carácter prioritario.

Como ha señalado Jorge Ibarra, a casi todas las comarcas de los Departamentos Oriental y Central les era común el atraso, y sus débiles vínculos con la corriente del comercio internacional. "Pero para superar el desarrollo era necesario, de acuerdo con Betancourt Cisneros, demoler las haciendas ganaderas, venderlas y poblar la región de ingenios, potreros y vegas, difundir el libro europeo y norteamericano, y organizar un sistema escolar que formase a la juventud en los nuevos principios que organizan al mundo" 21 .

Es cierto que El Lugareño trató de predicar con el ejemplo, al intentar, sin que el gobierno se lo permitiera, parcelar y casi regalar su propio mayorazgo para demostrar la autenticidad de sus verdaderas intenciones y propósitos. Así le explicaba sus proyectos a su amigo Domingo del Monte, el día de Navidad de $1841^{22}$ :

Por fortuna casi todos mis sitios están arrendados, y los dos que estoy fomentando están a cargo de dos mozos inmejorables, que son mi esperanza, para desempeñarme.

Respondo con mi cabeza de que tras mi ferrocarril, acometeré otras empresas no menos importantes. Asegurada esta victoria, respondo del camino de Santa Cruz que enlazará ambos mares; y respondo de realizar una Compañía de Colonización, que es la especulación más lucrativa en que puede entrarse, bajo estas bases. Primera: comprar hatos y animales, que no pasarán aquí de $50 \mathrm{a}$ 80.000 pesos y sólo en el valor de tierras, se harán sobre 400.000 pesos. Segunda: traer colonos blancos entre quienes repartir esas 1.500 a 2.000 caballerías, y los animales al precio de compra, y las caballerías a censo redimible y a 2 o 300 pesos. Sobre esto hablaré muy detalladamente con V. para que vea con cuánta facilidad y en cuán poco tiempo se convierten 100.000 pesos en un millón, siempre que la empresa sea acometida por una compañía protegida por el gobierno. Estas empresas no se frustrarán, yo respondo, sacándome avante de la actual de Nuevitas. Yo mismo iría por los colonos, yo me pondría a la cabeza de la colonia o pueblecito que se formase en la hacienda: y yo sería el hombre de confianza de los camagüeyanos.

Hombre de negocios al fin, utilitarista ilustrado y liberal, Betancourt Cisneros se enfrenta al bando conservador del Camagüey, entre los que destacaban su pariente Tomás Pío Betancourt, Francisco Iraola, José Vicente Mora y Carlos Mola Bautista, "enemigos encarnizados de todo lo que

21 "Regionalismo y esclavitud patriarcal en los Departamentos Oriental y Central de Cuba”, Estudios de Historia Social, núms. 44/47, Madrid, 1988, p. 119.

22 F. DE CóRDOVA, [4], pp. 98-99. 
pudiera constituir una amenaza a la continuación ininterrumpida del tráfico de esclavos", que representaban "los intereses más inmediatos de la clase terrateniente en el Cabildo principeño". En opinión de Ibarra, "la dependencia de los señores de hatos camagüeyanos con respecto a la trata, estaba determinada por el poco interés que habían mostrado desde principios de siglo por preservar las vidas de sus esclavos y en mejorar el índice de masculinidad en sus dotaciones", de ahí su hostilidad hacia los jóvenes liberales, reformistas y anexionistas, partidarios del cese del tráfico negrero.

"En el Puerto Príncipe, la contradicción fundamental en el plano político y económico se daba entre los reformistas o anexionistas que predicaban la necesidad de detener el comercio de esclavos y los propietarios de haciendas ganaderas o ingenios de vapor, que se aferraban a los viejos métodos de explotación del trabajo esclavo". Se trataba, pues, de una "contradicción entre los ideólogos de la clase que se planteaban los intereses de más largo alcance de ésta, es decir, de su desarrollo futuro, con la mayoría de clase que respondía únicamente a sus intereses del presente, a sus intereses más inmediatos". Por lo tanto, en la primera mitad del XIX, concluye Ibarra, el poder colonial, aprovechándose de esta contradicción, se apoyaba - en la comarca-, en el sector mayoritario de la clase terrateniente, "no en los comerciantes españoles, que en realidad tenían muy poco predicamento" 23 .

El Lugareño tuvo que enfrentarse, ciertamente, a la oposición de sus propios paisanos, su actitud sincera y directa le valió no pocos enemigos ${ }^{24}$ :

Pero una cosa es que la verdad y los hechos estén a la vista, y otra que haya traidores que la publiquen. A lo que parece el delito está en publicarlo, no en que el hecho exista; y en esto no van fuera de razón los camagüeyanos, porque el peor de todos los pecados es el escándalo: es así que yo soy el publicador, luego yo soy el gran pecador. Sin embargo, yo me las tengo tiesas y que quieran que no quieran han de oír: que más fácil es ser cultos que ser tenidos por cultos, ser virtuosos que persuadir que lo somos: más bella es la verdad desnuda, que la mentira con manto de púrpura; más útil la realidad en pequeño, que las apariencias en grande.

Y, desde los primeros momentos, se vio en la necesidad de defender su programa reformista, como hizo en su epístola publicada en la Gaceta del 2 de octubre de 183925 :

En primer lugar: quisiera que los hombres como V. no se entretuviesen en escribirle cartitas anónimas al Lugareño, sino que cada uno se echase al hombro

\footnotetext{
2.3 J. IBARRA, [21], p. 119.

24 F. DE CóRdova, [4], p. 240. Publicada en la Gaceta de Puerto Príncipe, 17 de agosto de 1839.

25 Ibidem, pp. 251-252.
}

R. I., $1998, \mathrm{n}^{\circ} 214$ 
la cruz de su pueblo, y sufriese la persecución, el escarnio y la mofa, hasta merecer la corona del martirio o la palma del triunfo. Más honroso es sucumbir bajo el estandarte de la verdad, que triunfar entre aleves en el de la impostura y los vicios. Si me tocase en suerte el martirio, vengan derrotas; no envidio la palma de los vencedores.

En segundo lugar: quisiera aquello de a Dios rogando y con el mazo dando; esto es, que al mismo tiempo que los hombres honrados escriban, lloren y regañen, se reúnan para negociar y establecer escuelas públicas gratuitas para los niños pobres de su comunidad, para que la educación se difunda entre todas las clases y todos los hombres de un pueblo, lleguen a cultivar su inteligencia hasta aquel grado que basta para saber lo bueno y lo malo, y poder discernir la verdad de la mentira, lo útil de lo perjudicial, lo justo de lo injusto. Esta es obra de la educación popular, y V. no me negará que más hace en favor de la razón y la conciencia humana un maestro de escuela que diez verdugos; y más vicios se corrigen en una escuela, que en cien cárceles y presidios.

En tercer, y por ahora último: quisiera que cada comunidad se reuniese para abrir los canales de la industria, y las fuentes de la riqueza pública; aquí, que se dividiesen las haciendas para que los pobres adquiriesen con facilidad una propiedad territorial que los obligase a amar su comunidad y su suelo y para que viniese mucha población europea de que carecemos y necesitamos urgentemente; allí, que se levantase una colonia o un pueblecito; allá, un caminito de hierro; acullá una línea de buques de vapor que lleven y traigan la civilización a todos los puntos de la Isla, y que nos faciliten modo de transportarnos al pueblo más inmediato, sin grandes fatigas y costos. Así, llegaremos a un pueblo de buen humor y talante, y podremos saludarle diciendo: la paz de Dios sea en este pueblo; aquí me depare la Virgen mucha gente alegre, contenta y rica que me obsequien, como al hermano ausente que vuelve a casa o viene a conocer a sus hermanos.

Pero, en cualquier caso, la luz del materialismo histórico, no debe impedir que se atisbe la amplitud de un debate que va más allá de las contradicciones de clase, para implicarse en un contexto de lucha por la liberación nacional, y por la necesidad de superar la trata como mecanismo coercitivo no sólo de la expansión económica sino, también, política. La supresión de la trata implicaba una alternativa de desarrollo económico y social, y, además, requería la transformación profunda de la estructura social de la región, mediante la implantación de una mano de obra inmigrada, de procedencia europea, que tendiera a generar una pequeñoburguesía agraria y, en definitiva, un campesinado que hiciera prosperar una de las comarcas más anquilosadas de Cuba. El Lugareño superaba, así, su origen aristocrático y terrateniente y se convertía en vanguardia de una inteligencia reformadora, que, por un lado, no confiaba en España, y, por otro, no consideraba un modelo digno de imitación el de la inquieta América española independiente. De este modo se lo recordó a José Antonio Saco, desde Nueva York, en carta del 19 de octubre de $1848^{26}$ :

Vas a escribir, dices, sobre anexión, y lo harás como un sacrificio que debes a la patria, es decir, contra tus sentimientos. Te comprendo, y ya quisiera que los dos nos viésemos ciudadanos de una nación independiente y libre, figurando entre los pueblos soberanos de la tierra. Pero entendámonos y convenğamos

26 F. DE CóRdOVA, [4], pp. 307-308. 
en que primero es la Patria que las vanidades de la nacionalidad, que el tiempo puede satisfacer, quizás con usura. ¿Te consta que somos hijos engendrados y paridos por España? ¿Y crees tú que hijos esclavos de Españoles pueden ser hombres libres? Te perdono el falso testimonio, y te remito a los guachinangos, y a los zambos, y a los Santa Annas, Flores, Monagas, etc. ¿Cómo podríamos nosotros conquistar nuestra independencia, y después sostener un gobierno libre? La anexión, Saco mío, no es un sentimiento, es un cálculo; es más, es la ley imperiosa de la necesidad, es el deber sagrado de la propia conservación. España no puede protegernos, ¿qué digo? España tiene que sacrificarnos a los intereses de la Europa, de España misma que con Rey o con Roque o sin ellos necesita de las potencias sus aliadas, de Francia y de Inglaterra para sostener una dinastía, una persona, un sistema, un principio que ellos allá adopten para sus gobiernos, aunque los diablos se lleven a los cubanos. Y si este es un hecho, ¿qué debe resolver un cubano previsor? Hemos de estarnos tendidos a la bartola y aguardando a que Europa se arregle, o España acabe de desarreglarse para recibir el decreto que nos destinen, el destino de Santo Domingo, de Jamaica, y las demás colonias europeas de América? ¡No, caray! Esto sería imperdonable, que teniendo a la mano la tabla de salvación, el gobierno más libre, el pueblo más fuerte, el ejemplo de la conservación social, sin perjuicio del progreso de la civilización y de la humanidad respecto del infeliz africano, queramos permanecer amarrados a un cuerpo corrompido que sólo puede infestarnos y hundirnos en su propio sepulcro. Si es preciso salvar nuestro país de la tempestad que le amenaza; si queremos marchar en las vías de la civilización y el progreso; si queremos ser libres y vivir entre hombres libres; si, en fin, necesitamos de una Patria donde criar a nuestros hijos y legarles nuestros huesos, preciso es separarnos de España bajo cuyo gobierno nunca, jamás, se formará el gobierno verdadero. Lo que diez o veinte trabajemos en la noble creación del Patriota, el gobierno español nos lo desbarata de un puntapié, y siempre estamos tejiendo la tela de Penélope que nunca se acaba, y hay que empezar de nuevo. ¿Quién ha de favorecer la creación del patriota, del hombre libre? ¿El que tiene interés en crear al colono y al esclavo? España formará condes y marqueses, palaciegos y sicofantas; pero no hombres libres.

Ello explica, también, la inclinación de nuestro hombre por el fomento de la educación popular, como un medio imprescindible para transformar la sociedad. El 2 de septiembre de 1839, en carta al gran pedagogo José de la Luz y Caballero, se escandalizaba ante la carencia de una escuela en Nuevitas, mientras que estaban abiertos al público cuatro billares ${ }^{27}$ :

Lo más presente se me olvidó. Está para cuajar mi proyecto de escuela en Nuevitas. Ya tengo conseguido los diez y seis pesos mensuales de los cuatro

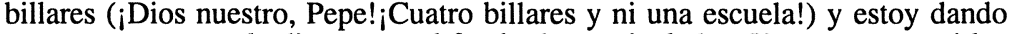
pasos para arrancarle diez pesos al fondo de matriculados. Vengan para acá los cien pesos que la Sociedad madre ha ofrecido para la escuela de Nuevitas.

\section{COLONIZACIÓN BLANCA VERSUS ESCLAVITUD}

La oposición de Gaspar Betancourt y Cisneros a la trata, su acerba crítica a los traficantes de esclavos queda patente en multitud de testimonios epis-

27 Ibidem, p. 173.

R. I., 1998, n. $^{\circ} 214$ 
tolares, sin embargo, no puede tachársele de racista, pese a la dureza de ciertas expresiones, pues no dejó de favorecer a la población esclava ${ }^{28}$. Es más, a través de su correspondencia, se observa con claridad su oposición a la institución misma de la esclavitud -no sólo al negocio de la trata-, por considerarla nefasta para el futuro de Cuba, tal como se aprecia en la siguiente epístola dirigida, el 5 de diciembre de 1841, a Domingo del Monte ${ }^{29}$ :

Acá [Camagüey] corre que en los dos últimos meses han entrado más de 2.000 negros en la Habana, lo cual nos tiene contentos, pues es prueba de que el General no ha consentido que se salgan con su gusto los ingleses.

Pero estos ratos de contento nos traen otros muy amargos e intranquilos. Se dice que entre los negros libres se descubrió hace poco una conspiración, con ramificaciones entre los esclavos, y todo dirigido por el cónsul inglés. Yo no he dado cabida a esta circunstancia, porque ni lo creo tan tonto que se relacione con negros, ni tan perverso que venga a perturbar la tranquilidad del país, cuando por otros medios más propios y dignos de su gobierno pueden aspirar al cumplimiento del tratado, que es a lo más que tienen derecho, según sus términos. Pero las cosas están tan malas por acá que ni aún racionalmente se puede hablar, porque o lo bautizan a uno de insurgente, o de abolicionista, que hoy es peor que insurgente.

Y unos meses más tarde le reiteróo:

Aquí se ha corrido que Turnbull ha sido expulsado de la Habana. Lo que V. me escribió hace tiempo: mucho miedo y poca vergüenza. Nuestros ricos propietarios y comerciantes están muy confiados en que ahora podrán engañar al gobierno inglés y continuar en el contrabando negrero.

Las gestiones del cónsul británico, Mr. Turnbull, tropezaron con todo tipo de inconvenientes por parte de las autoridades coloniales. El negocio de la trata pervivió pese a las pretensiones inglesas y, por ello, El Lugare$\tilde{n} o$ volvió a escribirle a Del Monte, a finales de 1843, en vísperas de la conspiración de la Escalera y su consiguiente represión, en términos sumamente irónicos ${ }^{31}$ :

28 Como en el testimonio de la siguiente carta a Luz Caballero, fechada en Pto. Príncipe, a 22 de marzo de 1840 (F. de Córdova: Op. cit., p. 181): “¡Qué de iniquidades! Cuando uno es síndico, entonces sabe algo más, hasta de lo que puede sospechar, en la materia, ¿V. quiere creer que un negrito, víctima del cólera, que lo fue porque le pegaron dos sinapismos y con el vendaje salieron cuero y carne y huesos, y perdió sus dos pies enteritos, lo hacen servir lo mismo que un hombre sano para cocinar, barrer, cargar muchachos, arriero, cogedor de ganado, calesero y todo? Pues así es la verdad; pero hoy se llevan chasco porque le he recogido al negro ciento cincuenta pesos de limosna, y hoy le han de otorgar su libertad mal que les pese, y en una tabaquería le mantienen y ganará lo menos tres reales diarios porque tuerce dos pesos de tabaco. Así se libertará del sufrimiento de trabajar de rodillas en cosas tan duras como las que le obligan a hacer, pues el fuete y el palo andan bobos en la casa; y comida, Dios la dé".

29 Ibidem, p. 90.

30 Ibidem, p. 113. Fechada en Nuevitas, $1^{\circ}$ de abril de 1842. Habana.

Ibidem, p. 151. Del Monte estaba a la sazón en Filadelfia. Betancourt le escribe desde La 
Os participo para vuestro consuelo que de esta isla están saliendo muchísimos buques para Africa, a traernos 20 ó 30.000 macuás o lucumíes para labrar la felicidad del país. Vos entendéis algo de lógica, y como con el dedo tocaréis el punto principal del negocio. Entretanto Matanzas grita que le manden tropa, que los negros mismos del triunvirato no están subordinados, que temen que la zafra no se concluya sin trifulcas como las pasadas. Nuestro gobierno, que se desvive por nosotros enviará tropas, y diz que armará escuadrones de caballería no de brutos guajiros, sino de los veteranos españoles licenciados, y los costos de este tren lo pagarán los hacendados como es justo, en virtud de que se les va a salvar sus intereses y hasta el pellejo, como bien lo verá V. con su lentecito lógico. Cualquiera dirá que mejor sería no traer negros, que sufrir estos costos, pasar estos sustos y correr todos estos riesgos; pero nosotros no podemos vivir sin el grajito del negrito, y sin tener a quien echarle fresco cuando estamos nosotros calientes. ¡Qué país tan desgraciado el nuestro! Dichoso V. que está fuera de él. No le aconseje a nadie que viva aquí.

La única alternativa posible, pues, era la atracción de inmigrantes blancos, bien como asalariados, o, en su caso, como colonos, pues El Lugareño se mostrará abierto a ambas posibilidades. El 18 de abril de 1841 anunciaba a Domingo del Monte la puesta en marcha de sus planes ${ }^{32}$ :

Ya di principio a mi plan de potrero con blancos. He empezado con 5 catalanes. ¿Os reís hombre? Dejaríais de ser poeta y habanero si no os rieseis de lo ruin, de lo pequeño de las miras y empresas del Lugareño. Pues bien, así lo pequeño, os prometo grandes resultados. Quiero que mi mayoral aprenda a gobernar blancos que no es una friolera para un tierradentro y luego que aprenda con 5 le pondré 10 , y al punto 20 y no más, para hacer un potrero que deje de 5 a 6.000 pesotes, y no quiero más tampoco.

$\mathrm{Su}$ correspondencia al respecto es sumamente rica. Así se dirigió, igualmente, a su sempiterno amigo y consocio de la Económica cubana, en la propia primavera de 1841 , con su inconfundible tono irónico ${ }^{33}$ :

Acá estamos contentísimos porque diz que ha pasado por Nuevitas una gran escuadra, cosa de 50 velas, no sé si 10 ó 20.000 hombres que vienen a reforzar la Isla, para que esos borrachos ingleses dejen de pensar en ella, ni en suprimir el contrabando negrero. Yo me alegro porque estoy por los blancos aunque sean los frailes que han expulsado de los conventos, y prefiero que tengamos hijos de frailes, a hijos de negros. Ojalá que nos mandasen todos los frailes que en España sobran, y aquí no alcanzan para la necesidad que tenemos de gente blanca.

¿Estará V. esperando noticias de mis cinco colonos, de los trabajos potreriles que hacen en el Horcón, de lo que se comen, de lo que duermen, etc.? Poco a poco, y no me lleve de carrera. Pierda cuidado que todo lo ha de saber, porque ya V. sabe que me he propuesto cacarear y campanear los resultados buenos o malos pues me llegan a noticia de todo títere negrero. Como yo vea el camino más clarito, encajo 25 isleños en el Horcón y otros 25 en el Ciego antes o en todo 1842. La fortuna de estos perros negreros es que yo soy un perro arrancado que si no, ya estaría el buque andando pues a Lanzarote a traerme a los nobles guanches que diz

\footnotetext{
32 Ibidem, p. 64 .

33 Ibidem, pp. 67-68. Del Monte, carta datada en Puerto Príncipe a 25 de abril de 1841.
}

R. I., $1998, \mathrm{n}^{\circ} 214$ 
domó mi pariente el Rey D. Juan Bethencourt, y ahora me toca a mí domarlos acá, tumbando jocumas y quiebrahachas en lugar de cabezas y piernas.

Y, poco tiempo después, le animaba a participar en el proyecto, al tiempo que resaltaba las particulares ventajas de sus contratas, pues, como dice en el texto, "no todos tienen un Najasa entero con 2.000 caballerías de tierra incultas y de primera clase". Pero, el negocio estaba también en el transporte de los propios inmigrantes ${ }^{34}$ :

Mi amigo don Juan Alvariño tiene acá un buen plan. Se propone con dos socios más (uno es capitán de un buque), poner un buque en la carrera de Canarias y España, su tierra, para traer blancos. Un viaje de Canarias aquí puede dejarle sólo de flete de pasajeros sobre 4.000 pesos ¿ No ve $\mathrm{V}$. a dónde esto va a parar? Otro lo sabe, hace lo mismo: competencia, rivalidad, baratura, guerra al buque negrero ¿no es verdad? Pues, señor, a proteger la empresa de Alvariño. Yo estoy más pobre que puta en cuaresma, pero me he suscrito con diez canarios en los términos que allá van en cuerpo y alma. Corra V. en pos allá -y haga sus indicaciones-. Hay dos o tres amigos que también piden, pero todavía no han presentado sus contratas, ni podrán ser como las más ventajosas, porque no todos tienen un Najasa entero con 2.000 caballerías de tierra incultas y de primera clase, y sobre 4.000 vacas, etc.

Es más, no todos los inmigrantes parecían igualmente idóneos para las tareas agrícolas, para resistir las duras jornadas de trabajo en el contexto de una cultura laboral surgida de la esclavitud. En este sentido, El Lugareño se lamentaba, el 18 de julio de 1841, de la pérdida de tres de sus labradores catalanes, que fueron atraídos por sus paisanos taberneros de la capital camagüeyana ${ }^{35}$ :

Los catalanes taberneros me sonsacaron tres de mis catalanes labradores. Yo tuve la culpa de haberlos traído para San Juan y San Pedro a la ciudad. No he querido coger otros tantos que se me han ofrecido a salario de 8 pesos y hasta 7 porque no quiero nada con catalanes, y espero mis 10,15 o 20 isleños que tengo encargados. Apunte lo que le digo: blancos han de ser los labradores del Horcón y el Ciego de Najasa aunque se oponga el mismo diablo: la fortuna del diablo es darse con el Lugareño.

E insistirá sobre el tema poco después, al tiempo que la franqueza y espontaneidad de su testimonio apunta hacia el verdadero carácter de estas contratas de labradores, donde el inmigrante perdía, incluso, su libertad personal, para convertirse en un semi-esclavo, al adquirir un estatuto legal ligado a su responsabilidad pecuniaria respecto al contratista ${ }^{36}$ :

34 Ibidem, pp. 71-72. Camagüey, 22 de mayo de 1841.

35 Ibidem, pp. 81-82.

36 Ibidem, p. 85. Camagüey, 30 de julio de 1841. 
No recuerdo si comuniqué a V. que para San Juan traje los catalanes a divertirse, y los taberneros tuvieron potencia de sonsacarme tres: me quedan dos hombres buenos, y están contentísimos; los tres están peor que los dos en todo sentido, y me alegro en el alma. Deje V. que vengan diez canarios que he encargado y verá V. cómo se quedan en Najasa, aun cuando no les acomode trabajar a salario. Si quisieren quedar libres les daré tierras, vacas, bueyes, etc. para que por sí trabajen y me paguen una renta moderada: yo he de poder poco o en Najasa han de trabajar más blancos que negros.

Esta parece ser la línea de actuación predilecta de El Lugareño, la colonización de sus vastas e incultas propiedades camagüeyanas mediante la atracción de "cuantos matrimonios me manden", aunque cuestionando la sinceridad del gobierno respecto del fomento de la población blanca ${ }^{37}$ :

A nuestra vista le informaré de mi plan de colonización, si el gobierno o esa maldita Junta de población quiere hacer algo: yo reparto tierras y animales a cuantos matrimonios me manden. Yo pienso tratar directamente con la Junta de población, y se van a ver en el compromiso de acerptar mis proposiciones, o dejarse quitar la careta y que nos desengañemos de que no quieren población blanca.

A partir de entonces, Gaspar Betancourt Cisneros se implicará cada vez más en su extracción de "guanches" de las Islas Canarias con destino a sus propiedades camagüeyanas, y animaba a sus amigos a imitarle en la empresa $^{38}$ :

Si os avistáis con Victoria decidle que os cuente el estado de una expedición que por mi cuenta y riesgo viene de Santa Cruz de Tenerife para trabajar en el Ciego de Najasa. Por el momento debo recibir 20 guanches de 16 a 30 años de edad. Ya os daré razón de todo luego que estén aquí. Por el mismo conducto voy a encargar otros 20 para el Horcón. Podéis estar seguro de una cosa: o yo me arruino, o pueblo a Najasa de hombres blancos: contad con ello, y decid que alguno me quite el derecho de arruinarme por meter blancos en Najasa. Y, ¿qué podrá suceder? Nada: millares se han arruinado por traer negros, por emborracharse, por putear, por robar, por jugar, por guapear. ¿Podrán achacar mi ruina a alguno de estos motivos? No: dirán que fui un loco; ¡muy bien!, esta es una locura juiciosa, y sóplese V. esa antítesis.

Creo se realizará otra empresa de cien colonos isleños. Estoy recogiendo firmas y ya tengo sobre sesenta colonos pedidos entre ocho personas pudientes. Así tal vez los meteremos por camino más seguro; bien que la verdadera causa que los compele a ello es la falta de introducción de negros. Cuando se van convenciendo de que el cuento no es cuento, se van disponiendo a gastar en traer blancos.

Paralelamente, El Lugareño se deshacía en alabanzas sobre la laboriosidad de sus inmigrantes isleños, que trabajaban voluntariosamente, "al

37 Ibidem, pp. 121-122. Pto. Príncipe, 31 de junio de 1842.

38 Ibidem, pp. 131 y 137. Del Monte, Camagüey, diciembre de 1842 y Pto. Príncipe, 2 de marzo de 1843 , respectivamente.

R. I., $1998, \mathrm{n}^{\circ} 214$ 
igual y junto con mis negros, sin distinción, sólo que comen aparte en rancho como soldados", o incluso mejor que "mis excelentes negros" 39 :

Mis colonos siguen perfectamente, contentísimos todos, y no dudo que aun cuando les ofrezcan mayor salario, no se irán de mi casa, pues ellos saben cómo se trata la barriga y el cuerpo en otras fincas, y preferirán un par de pesos menos en mi casa. Trabajan bien, al igual y junto con mis negros, sin distinción, sólo que comen aparte en rancho como soldados. Ahora me empeño en asociarme algunos propietarios jóvenes para que hagamos entre varios un pedido a Canarias de 50 ó 60 labradores, a fin de ir metiéndolos por el aro de tener gente blanca en el monte. Hecha la $2^{\mathrm{a}}$ expedición no dudo que lograré otras muchas.

Haré que Carrera vea trabajar en los campos de Cuba, en trabajos criollos rellollos, mi cuadrilla de guanches. Irá ese testigo ocular a la Habana, y no le desmentirán. Entretanto puede V. bajo mi responsabilidad asegurar que trabajan más y mejor que mis excelentes negros, y cuenta que mis negros trabajan voluntariosamente. No doy otra prueba que el trato que tienen, el cual es el mismo que los guanches, mismas horas, mismos trabajos, mismos alimentos, etc. y no hay látigo ni cepo, ni prisiones ni nada. Pero la censura no me deja decir nada de colonización, ni publicar nada sobre esta cuadrilla en que haría sin duda comparaciones de trabajadores a trabajadores. ¿Qué quiere decir esto? ¡Claro está! que [no] se quiere oír la verdad: que sólo se quiere meter negros en el pais: que nos llevarán los diablos, si la fuerza de la opinión y moralidad pública no hace que la gente moderna se deje de comprar negros, y metan blancos.

En agosto de 1843, en los instantes en que Domingo del Monte partía rumbo a Nueva York, intentando escapar de las consecuencias de la delación del poeta Plácido (Gabriel de la Concepción Valdés), en relación con la Conspiración de la Escalera, su amigo Betancourt Cisneros, encabezaba su carta con estas palabras ${ }^{40}$ :

Poeta mío: en momentos de avisarme para ir al Ciego de Najasa, a colocar cinco guanches más que me han venido de Canarias, llega mi amigo y discípulo don Antonio Freire a comunicarme su partida para New York, y quiero escribiros cuatro letras.

Con la información disponible no podemos cuantificar el número de isleños que Gaspar Betancourt Cisneros atrajo hacia sus propiedades de Najasa y el Horcón. Vázquez Galego apunta una cifra de tres millares de colonos canarios ${ }^{41}$, si bien su discurso se mueve en el amplio contexto del

39 Ibidem, pp. 139 y 141. Del Monte, Camagüey, 2 y 30 de abril de 1843, respectivamente.

40 Ibidem, p. 146. Pto. Príncipe, 10 de agosto de 1843.

41 A. VÁZQUEZ GALEGO, La consolidación de los monopolios en Camagüey, en la década del veinte, La Habana, Ed. Arte y Literatura, 1975, p. 25: "A los tres mil isleños traídos a Camagüey en la década del cuarenta del siglo anterior, por Gaspar Betancourt Cisneros, para blanquear a Camagüey y ponerlos al servicio de la industria, se sumarían los españoles e isleños (de las Islas Canarias) desmovilizados de La Trocha. Había el criterio reaccionario de que el asalariado blanco era más hábil en el aprendizaje y manejo de la industria que el negro. Cientos de isleños y españoles fueron incorporados a los nuevos centrales construidos en Ciego y Morón, centro, ..., de la mayor concentración industrial de la provincia de Camagüey". 
desarrollo económico del Camagüey durante el siglo XIX y de cara a centrar su investigación en el análisis de la gran expansión cañera de la provincia que, en efecto, tendría lugar a partir de las dos primeras décadas del siglo $\mathrm{XX}$.

\section{¿ANEXIÓN O INDEPENDENCIA?}

¿Qué alternativas políticas tenía Cuba en los inicios de la década de 1840 ? El Lugareño se mostró siempre atento a los vaivenes de la realidad política internacional, como puede observarse en el siguiente fragmento del 3 de enero de 1841, un día antes, por lo tanto, de que se diera a la estampa en Liberia, antes La Palma, un manifiesto insurreccional que invitaba, presuntamente desde Canarias, a la independencia de Cuba y Puerto Rico, para sumarse de este modo al proceso emancipador canario ${ }^{42}$. Decía, pues, Betancourt Cisneros en carta a don José de la Luz y Caballero ${ }^{43}$ :

No sabemos si será cierta una bomba que corre sobre los negocios políticos de la Francia. Acá corre que el rey está preso, y esto me huele a chamusquina. Corre también otra de revoliscas en las Islas Canarias. Allá lleguen y acá no peguen. Nosotros, haciendo ferrocarriles e impugnando a Cousin mientras esos brutos se cortan el pescuezo o se mueren de miseria. Lo que tiene de verdad muy afligidos a los propietarios de por acá es la noticia de Mr. Turnbull, o sea la tenaz resolución de Inglaterra a hacer cumplir el tratado.

Aparte, pues, de su temprana relación con empresarios estadounidenses, "tengo entre manos dos empresas con yankees. Una de minas, que tratan de comprar, otra de accionistas para la segunda parte de nuestro camino", escribió a Del Monte unos meses después ${ }^{44}$, también, como hemos visto, se preocupó muy mucho de sus contactos con el representante de Inglaterra, y ello era lógico, además, por el papel de oposición a la trata que jugaba el cónsul inglés David Turnbull. "Haga ver a Turnbull que aquí estamos mal parados en el día, y que una correspondencia con él, aunque fuese la más inocente se miraría como un crimen", afirmaba en otra comunicación a Del Monte del 30 de julio de 1841, y añadía a continuación ${ }^{45}$ :

Como los negreros han sabido que el General [Jerónimo Valdés y Sierra] se ha hecho de la vista gorda se han tragado, los muy brutos, que con ellos no puede Inglaterra, y que ahora transplantarán el Africa entera a la Isla. Se han engreído y hablan gordo, y esgrimen armas prohibidas y vedadas por la buena fe, pues propalan que nosotros aspiramos a la emancipación de los esclavos, y a

\footnotetext{
42. M. DE PAZ SÁNCHEZ, Amados Compatriotas. Acerca del impacto de la emancipación americana en Canarias, Santa Cruz de Tenerife, "Taller de Historia", CCPC, 1994, pp. 131-133.

43 F. DE CóRDOVA, [4], p. 188. Pto. Príncipe, 3 de enero de 1841.

44 Ibidem, pp. 81-82. Camagüey, 18 de julio de 1841 , cit.

45 Ibidem, pp. 83 y 85 , cit.
} 
la de la Isla, cuyas ideas las acoge siempre el gobierno, y bastan para frustrar las intenciones y proyectos más santos en bien del país.

Por honor de Inglaterra y de la civilización, no creo que aspire a arruinar esta preciosa Isla, y a un pueblo que en nada le ha ofendido, sólo por quitar un rival de azúcar a sus posesiones de la India: esta idea es muy miserable y muy propia de hombres que no alcanzan a ver más allá de sus cañaverales, ni entienden de otros cálculos que de las zafras que hayan de producirles tantos negros...

Pero, nuestro hombre, que incluso había movido todas sus influencias para proteger a un tal Joice, súbdito inglés que había sido denunciado por unos catalanes por afirmar que la Isla sería inglesa en cuestión de meses, venía insistiendo a Del Monte, al menos desde junio de 1841, en la necesidad de protegerse de las acusaciones de anglofilia que le habían lanzado sus conservadores paisanos ${ }^{46}$ :

La última carta de V. me ha hecho desistir de continuar escribiendo sobre colonización blanca de una manera tan ostensible para los negreros. Ya mi amigo el censor me ha manifestado alguna inquietud al ver que en la Habana no se escribe ni se proyectan expediciones a Europa... En fin, nosotros vemos como la luz del día, que entre la debilidad de España, la omnipotencia de Inglaterra, y la imprevisión de los cubanos, esta preciosa Isla irá al abismo profetizado por Tocqueville; salvo que Dios, por uno de aquellos acontecimientos que la inteligencia humana no puede prever ni alcanzar, la liberte de su total ruina.

Diga V. a Turnbull que no me comprometa, pues ya estoy sobradamente comprometido con las opiniones que he dado a conocer en todo tiempo... Observe V. las marcas de tinta hechas en la Gaceta, y sepa que todo eso se dirige a hombres como Iraola, Tomás Pío [Betancourt] (y millares de ellos) que tuvieron el arrojo de decirme en mis barbas que yo era inglés; como si un hijo de Jefferson y de Washington pudiera jamás dejar de ser americano, ni entrar en infamias de que sólo son capaces los hombres que no tienen otro Dios, ni otra Patria, ni otra Humanidad, que sus negros, su interés y su despotismo-esclavos por tener esclavos.

A fines de ese mismo año escribió una vez más, pero ahora con cierto desaliento patriótico, a su amigo Del Monte ${ }^{47}$ :

¿Qué esperanzas hay que fundar en los Estados Unidos? Yo sé que nuestras circunstancias se agravan de día en día: que España no se alienta aunque le den caldo de América, y que John Bull y Belcebú y Proserpina son tres personas distintas y un solo diablo verdadero. Estoy en mis trece, compadre: entre la impotencia de España, y la omnipotencia humana de Inglaterra, vamos a quedar aplastados como una tortilla si Dios no nos mira en caridad.

Y algo parecido expresó en enero de 1843, con relación a unos presuntos rumores sobre la independencia política de Cuba, que estaba siendo promovida por emisarios ingleses ${ }^{48}$ :

46 Ibidem, pp. 78-80. Del Monte, Camagüey, 20 de junio de 1841.

47 Ibidem, p. 93. Camagüey, 12 de diciembre de 1841. 
He leído una carta en que se dice que los emisarios, misioneros y agentes diplomáticos de Inglaterra andan de casa en casa (son sus palabras) ofreciéndonos la independencia a trueque de la emancipación. ¡Terrible condición! Pero también dicen que amenazan con que a la mala se tomarán lo que a la buena nos proponen, porque diz que el gobierno metropolitano está vendido a las guineas e intereses de Inglaterra. $¡$ Qué pícaros esos ingleses! Se han propuesto arruinarnos y de un modo o de otro lo conseguirán.

Durante su exilio en Nueva York, su discurso político adquiere dimensiones más profundas. Gaspar Betancourt y Cisneros no es un anexionista vulgar, de algún modo, tal como se refleja en algunas de sus epístolas, quiere aparecer como objetivo e imparcial. Sabe que la mayoría de los defensores del anexionismo lo son para garantizar sus intereses esclavistas, $\mathrm{y}$, por contra, parece creer en la posibilidad de obtener, al menos, el apoyo coyuntural de los Estados Unidos, contra Europa y contra "nosotros mismos". Se trataba de la única opción posible frente a la dominación española, cuya presencia en Cuba iba a depender, en el próximo futuro, de una acción de fuerza y de coartación de los derechos y libertades de los cubanos ${ }^{49}$ :

De esta clase de creyentes hay dos partidos, unos que ven en la anexión el medio de conservar sus esclavos, que por más que lo oculten o disimulen es la mira principal, por no decir la única que los decide a la anexión; otros que creen en la anexión el plazo, el respiro, que evitando la emancipación repentina de los esclavos, dé tiempo a tomar medidas salvadoras como duplicar en 10 ó 20 años la población blanca, introducir máquinas, instrumentos, capitales, inteligencias que reemplacen y mejoren los medios actuales de trabajo y de riqueza. En fin, Saco mío, todos buscan en la anexión la garantía, la fianza del gobierno sabio y fuerte de los Estados Unidos contra las pretensiones de Europa, no menos que contra nosotros mismos que mal que pese a nuestro amor propio somos del mismo barro que los que han logrado hacerse independientes, pero no pueblos libres y felices. He aquí en compendio lo que yo he oído a los principales cabecillas del proyecto de anexión.

Los anexionistas creen que la política de España está fijada, y está fijada del único modo que puede prolongar su dominación en Cuba por algún tiempo más. Un ejército permanente que oprima y aterre al pueblo; protección a la introducción de negros y fomento de la esclavitud; oposición consiguiente a la inmigración de blancos; restricciones al comercio extranjero; división sistemática entre españoles y cubanos; coartación y negación de derechos políticos y religiosos; contribuciones e impuestos hasta por respirar; exclusión de los cubanos de todo puesto o empleo en que pueda tener influencia en la educación de la juventud, en el gobierno, en las leyes, y en las simpatías de los criollos. Tal es la punta, dicen los anexionistas concienzudos, a que tiene que sujetarse el gobierno de España en Cuba para asegurar su dominación. Si esto es lo que conviene a la Isla; si esto es lo que asegura la paz, la propiedad, la seguridad, el progreso de un pueblo civilizado; si a esto es a lo que aspiran los cubanos; entonces, dicen los señores anexionistas, con su pan se lo coman y a buenas horas

48 Ibidem, p. 134. Del Monte, Puerto-tasajo, 29 de enero de 1843. Subrayado en el original. El tasajo - carne salada - como es bien sabido, era la comida habitual de la población negra de las plantaciones, acompañada de arroz.

49 Ibidem, pp. 313-314. A José A. Saco, Nueva York, 20 de febrero de 1849.

R. I., $1998, \mathrm{n}^{\circ} 214$ 
les alumbre el sol de la Iberia; pero entretanto cierto es e inevitable que bañe a los cubanos el sol de América, y allí será el conflicto entre las dos luces.

Su intuición profética le lleva, además, a concebir el drama de Cuba, el estallido, más temprano que tarde, de un conflicto revolucionario, y así se lo expresó a José Antonio Saco en una carta del 3 de abril de $1849^{50}$ :

Sin duda es desgracia mía ver todas las cosas de Cuba de mal a peor. Me represento a Cuba como una linda muchacha a merced de déspotas, de pícaros, y de cobardes; y por más que busque entre las tres clases a un salvador, por Dios que no sé cuál de ellos encontrará la salvación. En cada pulgada de Cuba, en su gente, en su vecindario, en todo, veo el combustible acumulado de antemano y que una hora menguada ha de inflamar sin que lo evite otro poder que el de Dios.

Posteriormente le informó sobre la estancia en Nueva York del padre Varela ${ }^{51}$ - cuyo "reino" ya no era de este mundo-y de su pariente Tomás Pío Betancourt, reacio a la independencia, y aprovechó para mostrarle su pesimismo sobre las esperanzas de los "anexionistas pacíficos", que anhelaban, en vano, reformas y cambios positivos de la tutela española. Otra cosa eran los Estados Unidos, por la capacidad de esta nación para hacer prosperar a "cualquier país que cojan entre sus manos" 52 :

En mi anterior te di noticias de Varela y Tomás Pío, que están aquí buenos y sanos. A Varela no hay modo de sacarle una palabra sobre Cuba, ni en pro, ni en contra: su reino no es de este mundo. En cuanto a mi pariente es otra cosa. A todo prefiere la unión a la madre patria, bien que con un buen gobierno, justo, liberal, enérgico que España nos debiera dar. De independencia absoluta no hay que hablarle, porque él bien se sabe que sería un tomo más agregado a la Historia de los desórdenes, desgracias y ruinas de América. La anexión a los Estados Unidos sería otra cosa: la gente yankee es entendida en esto de gobierno y hacen prosperar cualquier país que cojan entre sus manos; pero esa anexión debería hacerse pacíficamente, por convenio entre partes, España, Cuba, Estados Unidos, cielo, infierno y purgatorio, mar y tierra. Este es saquista, como dicen unos, y retranquero, como digo yo, que con esa divisa he bautizado un partido político, cuyos jefes sois vosotros los hombres prudentes, los anexionistas pacíficos, y los que esperáis que España nos prepare, nos enseñe, nos adiestre y perfeccione en el arte de gobernar y de ser libres para que en el último tercio de la eternidad, o en las vísperas del Juicio Final podamos ser nación independiente, $o$ anexarnos a quien nos acomode. El partido retranquero, encargado de sujetar la burra, o parar o contener el locomotor, para que no haga pedazos el tren de carros, parece que ignora que Parejo, Pastor, Forcade y toda la cofradía de negreros con sus padrinos, madrinas, testigos y asistentes están soplando en Cuba negros de Africa a millares; y juran que son del Brasil; y quieren encandilar a Inglaterra, y dicen que ésta no tiene que meterse en cuentas ajenas, y que los negros son la Providencia de Cuba, encargados de labrar la felicidad y bienestar de sus habitantes. Ya ves, Saquete, cuánto importa, en las presentes circunstan-

50 Ibidem, p. 317. Datada, lógicamente, en Nueva York

51 E. REYES FERNÁNDEZ, Félix Varela. 1788-1853, La Habana, Ed. Política, 1989.

52 F. DE CóRDOVA, [4], pp. 331-332. A Saco, Nueva York, 7 de agosto de 1849. Subrayado en el original. 
cias y revueltas del mundo, sostener la retranca. Sujeta pues, la burra que no se desboque, pero asegúrate bien no sea que des una costalada.

El Lugareño no tardó, sin embargo, en derivar hacia planteamientos más radicales, en mostrarse partidario de la libertad de Cuba. Tal parece deducirse de la epístola que, en tono polémico, dirigió a su colega José L. Alfonso, en la primavera de $1852^{53}$ :

Dice usted "que en 1851 me oyó decir que la revolución de Cuba era necesaria a todo trance, y que agregué estas memorables palabras: Cuba libre, o aquí fue Cuba. Me explicaré. Convencido como estoy de que la revolución de Cuba es necesaria, inevitable, y que tiene que atravesar por entre escollos y peligros, creo que es preciso aceptarla con todas sus consecuencias, y una vez lanzados en ella la alternativa es sacarla libre (Cuba libre) o hundirnos en sus ruinas (aquí fue Cuba). Este es el pensamiento que he querido expresar; y si la alusión a Noya ha dado lugar a otra interpretación, reconoceré que me expliqué mal. Nadie se propone libertar a Cuba o asolarla; tememos que en la lucha de la libertad, si no triunfa y queda libre, quede arruinada.

Estas palabras de El Lugareño, desbordantes de cubanía, intuyen una vez más aspectos futuros de su patria. Este hombre, miembro por nacimiento de la rancia aristocracia camagüeyana, supo vivir acorde con las ideas más progresistas de su tiempo y, con indudable riesgo para su status social y, desde luego, para su propia vida, luchó por lo que, en aquella época, le pareció más justo y progresista. Supo oponerse, en fin, contra la esclavocracia, ese término utilizado por él para definir con precisión la pervivencia de una institución que, amparada por la metrópoli, convertía en esclavas a las propias clases dirigentes cubanas, "esclavos por tener esclavos", como diría, también, en cierta ocasión.

Gaspar Betancourt y Cisneros, known as El Lugareño, was an outstanding member of the Cuban intelectual and landing aristocracy during the first half of the $19^{\text {th }}$ Century. He supplies a most interesting case that may help to understand some essential aspects of the debate that took place in his time between the anti-slavery minority - who maintained that the slave working force checked the development of the sugar industry-and the majority of the great landing owners who still trusted in the ilimited exploitation of human resources linked to the slave trade and its agrarian uses. The letters sent by Betancourt to some of his friends and followers, notably to Domingo del Monte, are a first-hand testimony of the importance of the issue.

\footnotetext{
53 Ibidem, p. 360. Nueva York, 13 de mayo de 1852. Subrayado en el original.
} 